\title{
MSL Complex Associates with Clusters of Actively Transcribed Genes along the Drosophila Male X Chromosome
}

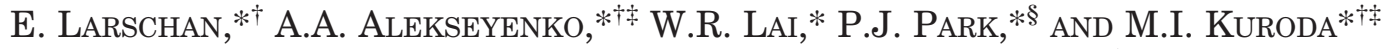 \\ *Harvard-Partners Center for Genetics and Genomics, Brigham \& Women’s Hospital, 'Department of Genetics, \\ Harvard Medical School, ${ }^{\ddagger}$ Howard Hughes Medical Institute, ${ }^{\S}$ Children’s Hospital Informatics Program, \\ Boston, Massachusetts 02115
}

\begin{abstract}
Dosage compensation in Drosophila serves as a model system for understanding the targeting of chromatin-modifying complexes to their sites of action. The MSL (male-specific lethal) complex up-regulates transcription of the single male X chromosome, thereby equalizing levels of transcription of X-linked genes between the sexes. Recruitment of the MSL complex to its binding sites on the male X chromosome requires each of the MSL proteins and at least one of the two large noncoding roX RNAs. To better understand how the MSL complex specifically targets the X chromosome, we have defined the binding using high-resolution genomic tiling arrays. Our results indicate that the MSL complex largely associates with transcribed genes that are present in clusters along the X chromosome. We hypothesize that after initial recruitment of the MSL complex to the $\mathrm{X}$ chromosome by unknown mechanisms, nascent transcripts or chromatin marks associated with active transcription attract the MSL complex to its final targets. Defining MSL-complex-binding sites will provide a tool for understanding functions of large noncoding RNAs that have remained elusive.
\end{abstract}

Regulatory roles for noncoding RNAs are being discovered at an exciting rate, as biologists delve into a previously hidden RNA world. Although the roles of small RNAs are becoming relatively clear in many systems, mechanisms by which large RNAs regulate gene expression in the nucleus remain mysterious. Prominent examples are the RNAs involved in dosage compensation in mammals and in the fruit fly, Drosophila melanogaster.

Dosage compensation makes X-linked gene expression equivalent in males (XY) and females (XX). In Drosophila, this occurs primarily by increasing transcription of X-linked genes in males (Hamada et al. 2005; Straub et al. 2005). Two noncoding $\operatorname{roX}$ (RNA on X) RNAs, roX1 and roX2, interact with five MSL proteins to associate specifically with the male $\mathrm{X}$ chromosome in a finely banded pattern along its length (Fig. 1). Each protein component of the MSL complex is essential for dosage compensation, whereas the roX RNAs are functionally redundant (Meller and Rattner 2002). The MSL complex is required for site-specific acetylation of histone $\mathrm{H} 4$ on lysine 16 (H4K16ac) on the X (Turner et al. 1992; Bone et al. 1994), which is likely to have a key role in up-regulation of transcription (Hilfiker et al. 1997). Recently, H4K16ac has been implicated in destabilizing higher-order chromatin structure (Shogren-Knaak et al. 2006), suggesting a mechanism by which H4K16ac might influence transcription by causing increased accessibility of the transcriptional machinery to the DNA template.

The targeting of the MSL complex to hundreds of sites along the length of the polytene $\mathrm{X}$ chromosome, viewed at the resolution of light microscopy, has been known for many years (Fig. 1) (Kuroda et al. 1991). More recently, it was discovered that roX RNAs are required for this precise targeting to the majority of
A

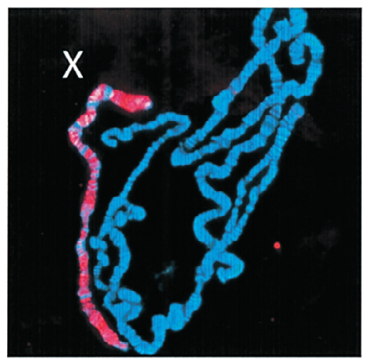

B

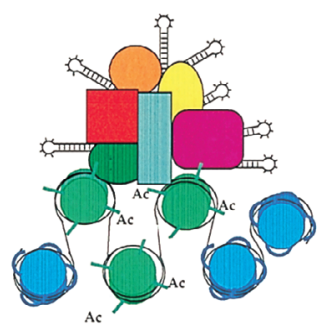

MSL1\& MSL2 core MSL3 chromodomain MOF $\mathrm{H} 4$ acetyltransferase MLE helicase roX1 RNA 3.7 Kb ] functionally roX2 RNA $0.5 \mathrm{~Kb}$, redundant

Figure 1. MSL complex binding to the male $\mathrm{X}$ chromosome on polytenes and schematic of the MSL complex. $(A)$ Immunostaining of the MSL3-TAP protein binding specifically to the male X chromosome. (Blue) DAPI staining for DNA; (red) MSL3-TAP immunostaining. (B) The MSL complex contains five protein and two noncoding RNA components. The actual organization and structure of the MSL complex are unknown. MSL1 and MSL2 components of the complex are essential for complex formation. MSL3 contains a chromodomain, a domain present in many chromatin-associated proteins. MOF is a histone acetyltransferase specific for $\mathrm{H} 4$ acetylated at lysine 16, and MLE is an RNA helicase. Two noncoding RNAs encoded on the $\mathrm{X}$ chromosome are present in the MSL complex, roX1 $(3.7 \mathrm{~kb})$ and $\operatorname{roX} 2(0.5 \mathrm{~kb})$. ( $A$, Adapted, with permission, from Alekseyenko et al. 2006.) 
sites on the X chromosome (Meller and Rattner 2002). Signature DNA sequences that could be responsible for the X-chromosome specificity of MSL complex binding have not been identified. There is evidence for spreading from roX genes in cis (Kelley et al. 1999; Park et al. 2002; Oh et al. 2003) and recognition of $X$ segments in trans (Demakova et al. 2003; Fagegaltier and Baker 2004; Oh et al. 2004), but the rules for target recognition are not known. Insertion of a strong enhancer into some ectopic positions on the X chromosome can create new cytological sites of MSL binding, suggesting that transcription can activate MSL recognition (Sass et al. 2003). However, the actual identities of direct MSL targets and their key features were largely unknown. As a first step to defining the targeting mechanism, we and other investigators have determined the genome-wide MSL-binding pattern in Drosophila embryos and cell lines (Alekseyenko et al. 2006; Gilfillan et al. 2006; Legube et al. 2006). Knowing the nature of these precise targets is a key first step toward understanding how MSL proteins and roX RNAs collaborate to bind the $\mathrm{X}$ chromosome and regulate $X$-linked genes.

\section{CHROMATIN IP ANALYSIS OF THE MSL COMPLEX ON HIGH-RESOLUTION GENOMIC TILING ARRAYS REVEALS A LARGE SET OF COMMONLY BOUND GENES}

To determine the precise locations of the MSL complex along the $\mathrm{X}$ chromosome, we designed genomic tiling arrays (NimbleGen) composed of 388,000 x 50-mers, spaced with 50-bp gaps along the entire nonrepetitive $\mathrm{X}$ chromosome $(\sim 22 \mathrm{Mb})$, and most of chromosome $2 \mathrm{~L}$ ( 19.6 Mb). We performed chromatin immunoprecipitations (ChIPs) with modifications designed to optimize our specificity including using a TAP epitope-tagged MSL3 subunit expressed from the native msl3 promoter as our affinity reagent. Three different cell types were used for our analysis: SL2 cells (embryonic origin), Clone- 8 cells (larval wing imaginal disc), and late-stage embryos (mixed cell population)

We compared binding clusters identified on the X chromosome versus $2 \mathrm{~L}$ and found strong enrichment for the $\mathrm{X}$ chromosome (Alekseyenko et al. 2006). For example, in multiple analyses of Clone- 8 cells, 972 binding clusters were identified over the $\mathrm{X}$ chromosome, whereas none were seen on chromosome $2 \mathrm{~L}$, confirming the chromosomal specificity of MSL binding. Biological replicates identified a strongly reproducible set of binding clusters. Furthermore, when binding patterns among different cell types were compared, a strong degree of overlap was observed (Fig. 2) (Alekseyenko et al. 2006). When we compared the lists of genes clearly bound by the MSL complex in SL2 cells, Clone-8 cells, and embryos, we found about 600 genes that were common to all three data sets. A map of MSL-binding clusters along the entire euchromatic X chromosome graphically demonstrates the conservation of MSL-binding sites in different cell types (Fig. 2).

\section{COMPARISON WITH EXPRESSION MICROARRAYS REVEALS THAT THE MSL COMPLEX PREFERS EXPRESSED GENES, WITH STRONGER BINDING TOWARD THE 3' END OF TRANSCRIPTION UNITS}

In parallel with our ChIPs, we purified RNA from MSL3-TAP-tagged SL2 and Clone-8 cells and performed expression analyses using Affymetrix Drosophila microarrays. When the annotated genome was aligned with our expression and binding data, we saw a clear correlation of binding with expressed genes (e.g., red genes in Fig. 2) and not with nonexpressed genes (black in Fig. 2) or intergenic regions. When quantified, about $90 \%$ of the binding clusters were within expressed genes, whereas only $7 \%$ were within nonexpressed genes and less than $3 \%$ were in intergenic regions (Alekseyenko et al. 2006). The MSL-binding site map of the entire euchromatic X chromosome indicates that there are clusters of MSL-binding regions along the $\mathrm{X}$ chromosome that correspond to domains of active transcription (red genes in Fig. 2).

Furthermore, MSL binding was clearly not centered at 5 ' regulatory regions, but often appeared to cover a large portion of each transcription unit. To analyze this objectively, we scaled all bound genes to the same relative length and found that binding on average was enriched over the middle and 3 ' end, and away from the 5 ' end (Fig. 3). This was seen in genes of all lengths, and was most evident in long genes. This pattern is clearly distinct from typical sequence-specific transcription factors, which bind to discrete target sequences generally in $5^{\prime}$ regulatory regions (Ren et al. 2000). The pattern is also distinct from general transcription factors thought to increase accessibility of promoter regions to RNA polymerase (Kim et al. 2005). The association of the MSL complex to bodies of genes, with stronger binding toward the 3 ' end, is instead reminiscent of binding patterns for factors that regulate transcription elongation or termination (Simic et al. 2003; Carrozza et al. 2005; Keogh et al. 2005; Kizer et al. 2005; Rao et al. 2005).

Previous analyses of X-chromosome specificity relied largely on comparing the whole $\mathrm{X}$ chromosome to autosomes for sequences that might specify regulation by dosage compensation. With our newly identified set of precise binding sites, we focused our search for sequences that were enriched in these specific segments, when compared to autosomes or to X segments that were not bound by the MSL complex. These searches once again failed to identify unique sequence signatures that might specify MSL recognition.

\section{ATTRACTION OF MSL COMPLEXES IS LINKED TO GENE ACTIVITY OR TO THE CHROMATIN CONTEXT OF TRANSCRIBED GENES ON THE X CHROMOSOME}

Since SL2 cells, Clone- 8 cells, and embryos display very similar patterns of MSL binding, it is possible that degenerate sequences have evolved on commonly expressed genes to identify them as MSL targets (Gilfillan et al. 2006; Legube et al. 2006). To test whether sequence 


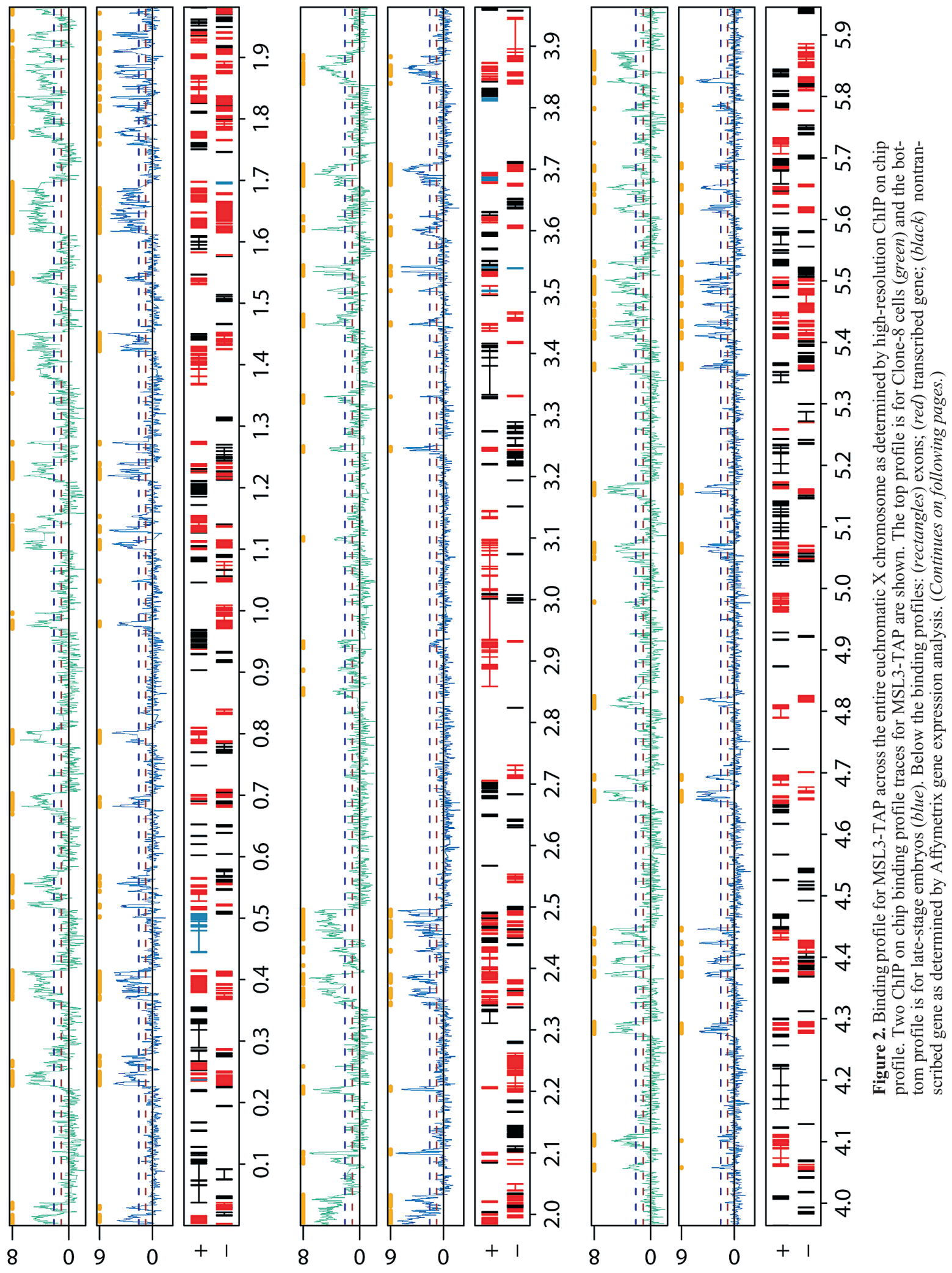



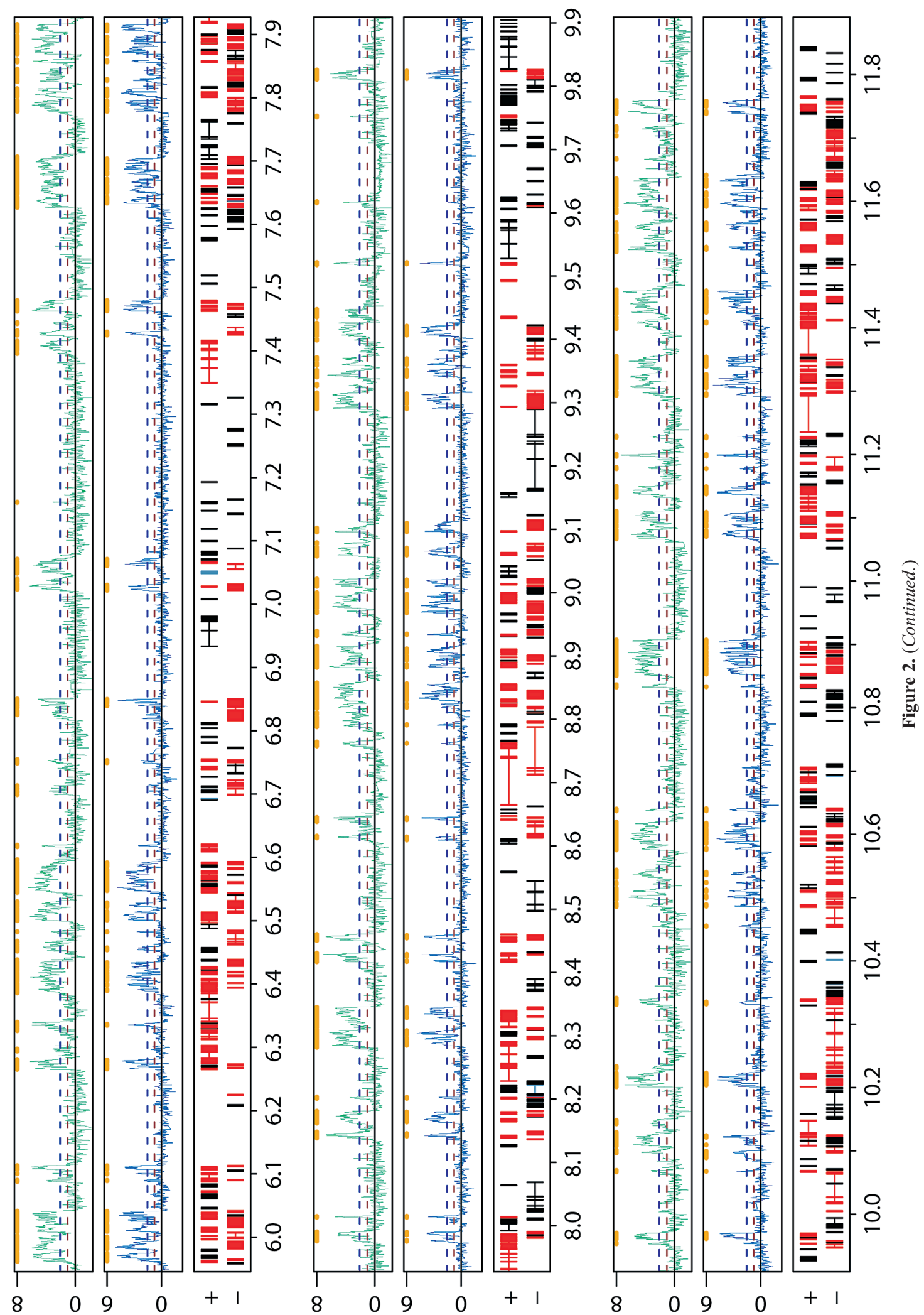

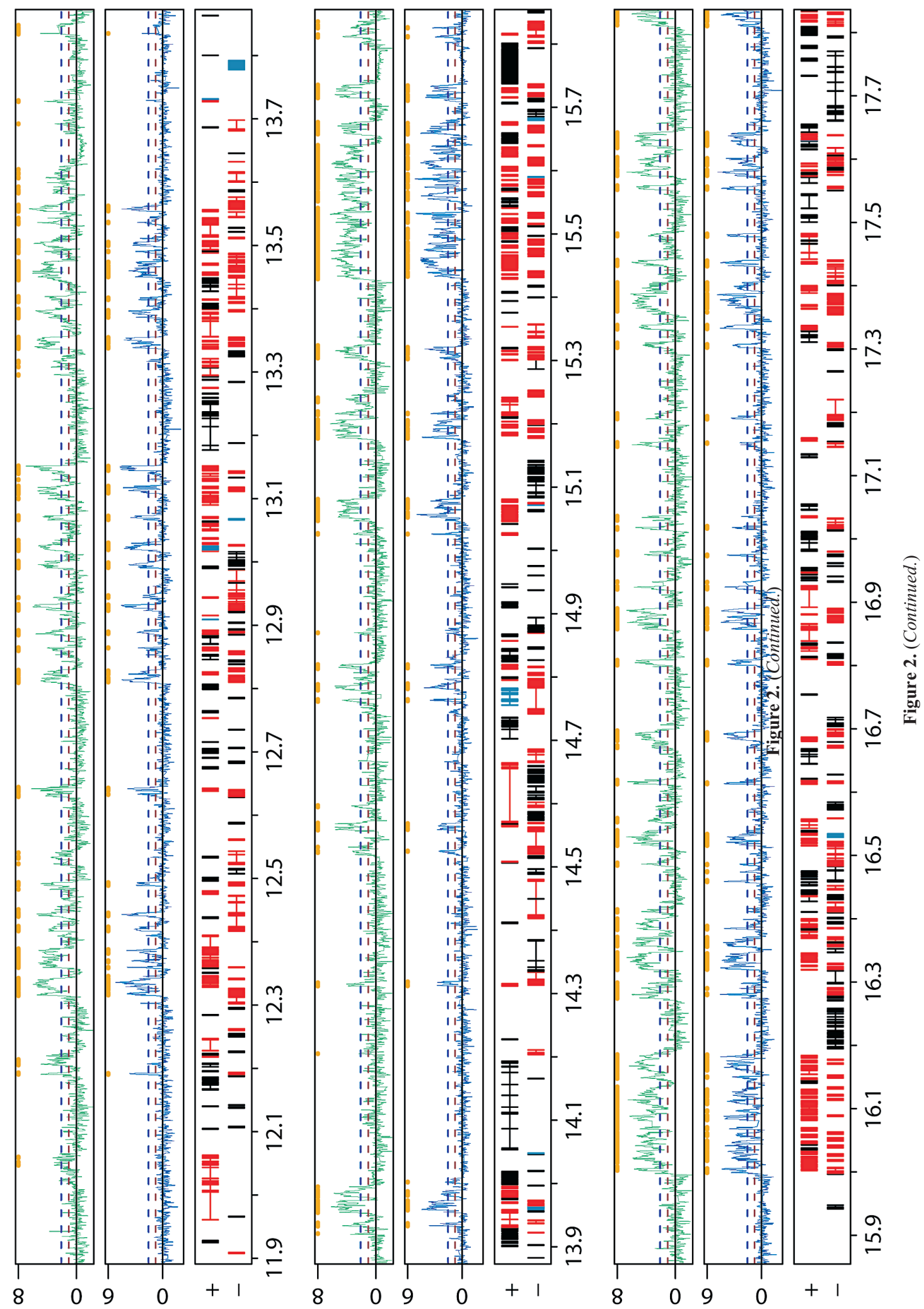


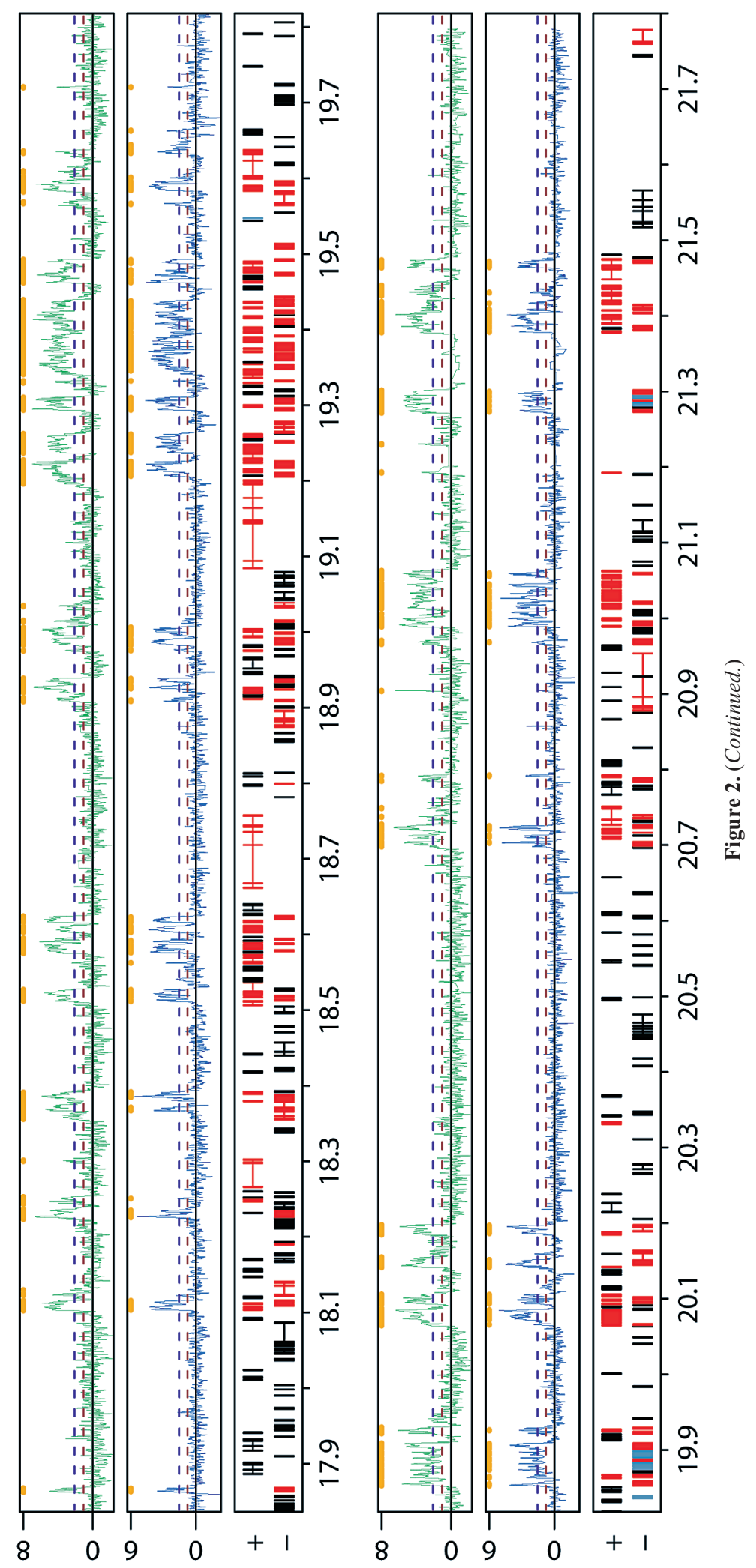




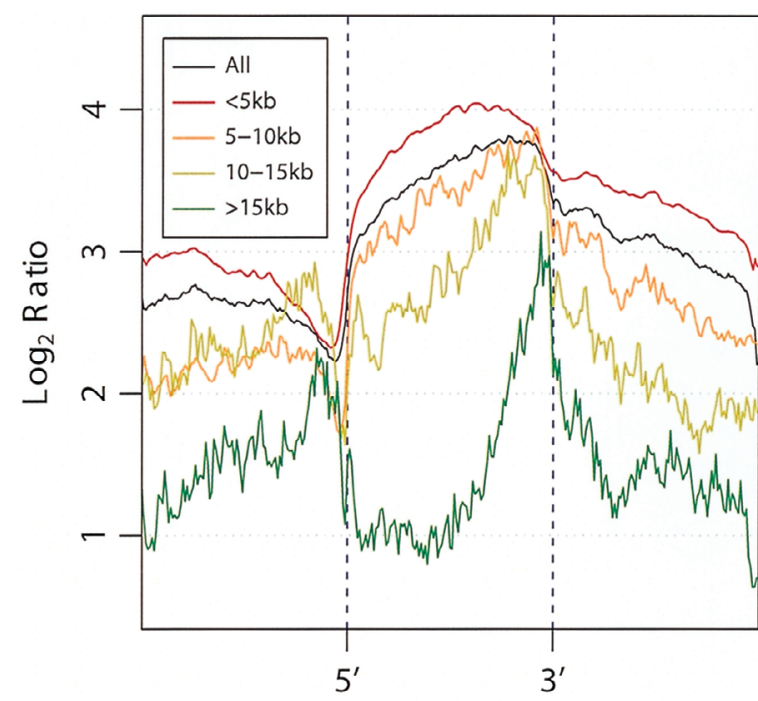

Scaled Distance (gene)

Figure 3. Average profile of MSL binding to scaled genes from different size classes. Average binding profiles for Clone-8 cells. (Black) Average profile for all bound genes. (Red) genes $<5 \mathrm{~kb}$; (orange) 5-10 kb; (yellow) 10-15 kb; (green) $>15 \mathrm{~kb}$. (Adapted, with permission, from Alekseyenko et al. 2006.)

alone is sufficient for MSL recognition, we asked whether there were any genes that were bound in one cell type but unbound in the other cell type. Using strict bound/unbound criteria, we identified 14 genes that were bound in Clone8 cells and not in SL2 cells, and 2 genes that showed the opposite pattern (Fig. 4) (Alekseyenko et al. 2006). We then asked whether or not differential binding correlated with differential expression in the two cell types. By comparing the relative expression values for these genes in two microarray experiments for each cell type, we found that all of these genes are differentially expressed, and the differential is much more than a twofold change that could be attributed to dosage compensation. Overall, a clear correlation between differential expression of this set of genes and MSL binding is evident.

Figure 4 (left) shows two examples of genes that are bound by the MSL complex in SL2 cells (top profiles) but are not bound in Clone-8 cells (bottom profiles) and are specifically transcribed in SL2 cells. Figure 4 (right) shows two examples of genes that are specifically expressed and bound in Clone-8 cells. In each case, the gene of interest is centered below the profiles. We validated the binding and transcription levels of these candidates by real-time polymerase chain reaction (PCR) analyses for differential MSL3-TAP binding, MSL1 binding, H4K16 acetylation, and transcript level (Alekseyenko et al. 2006). The enrichment of MSL1 and site-specific acetylation of H4K16 both correlated well with differential binding of TAP-tagged MSL3 at these genes. Furthermore, real-time PCR analysis of RNA levels validated the expression microarray differences seen in the two cell types (Alekseyenko et al. 2006). Our results strongly suggest that sequence alone is not sufficient for MSL binding, because the same gene sequences can be clearly bound or clearly unbound depending on the cell type. Instead, our results suggest a model in which a majority of X-linked genes have evolved a mechanism to attract MSL complexes that is linked to gene activity or to the chromatin context of transcribed genes.

\section{SL2 specific genes}
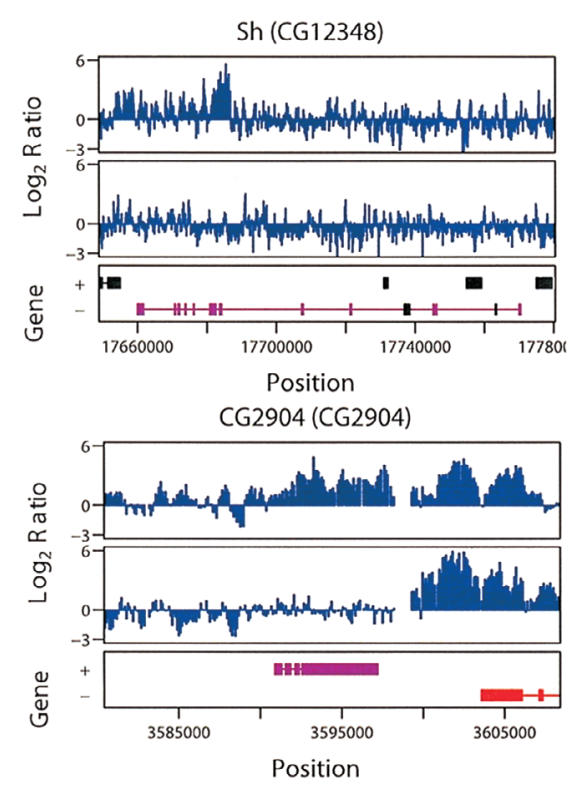

\section{Clone 8 specific genes}
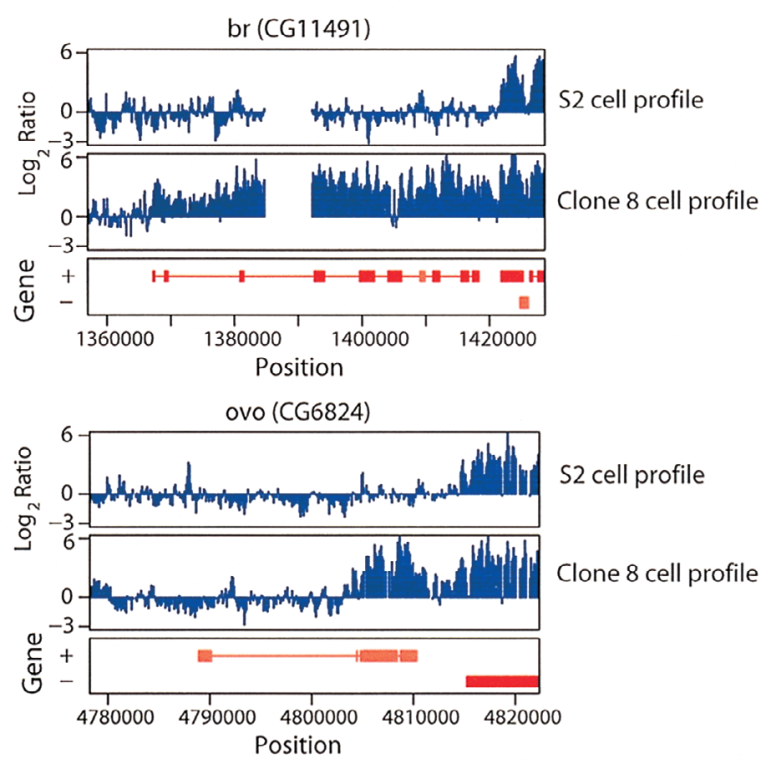

Figure 4. Sequence alone is not sufficient to specify MSL binding. Examples of ChIP-chip tiling along two genes that were bound in SL2 cells but clearly unbound in Clone- 8 cells (left) and two genes clearly bound in Clone- 8 cells but not in SL2 cells (right). (Top profiles) SL2 cells; (bottom profiles) Clone- 8 cells. The central gene is the one of interest in each case and is specifically transcribed in the cell type in which it is bound. For CG2904 and br, the whole gene appears covered by MSL binding, whereas the Sh and ovo genes show strong enrichment over the $3^{\prime}$ portion but not over the $5^{\prime}$ region. (Adapted, with permission, from Alekseyenko et al. 2006.) 


\section{CONCLUSIONS}

The MSL complex performs a specialized function in flies, but its characterization is likely to have broad implications regarding the mechanism by which chromatin modification factors search for and identify active genes. We have identified the X-chromosome-specific binding pattern of the MSL complex by ChIP-microarray analysis in several distinct cell types. In all cases, we see strong enrichment for the $\mathrm{X}$ chromosome and not for chromosome $2 \mathrm{~L}$ and strong enrichment over most active genes (Fig. 2). When the profiles of all bound genes are scaled to align at the $5^{\prime}$ and $3^{\prime}$ ends, we see a marked preference for the middle and $3^{\prime}$ ends of genes, rather than the $5^{\prime}$ end (Fig. 3). These data are consistent with a two-step model for MSL complex binding in which the complex first identifies the $\mathrm{X}$ chromosome via sequence elements or noncoding RNAs and subsequently identifies target genes by recognition of chromatin modifications or nascent mRNA transcripts (Fig. 5).

The MSL-binding profile correlates well with that of its targeted modification, H4K16ac, on selected X-linked genes (Smith et al. 2001). The skew toward the 3 ' end of genes is unlike the profile of transcription initiation factors and instead reminiscent of factors that function in transcription elongation or termination. Together, our results suggest that the MSL complex is unlikely to function directly at the promoter like a typical transcription factor. An appealing idea is that an improvement of transcription elongation might improve ultimate mRNA production, perhaps by local recycling of RNA polymerase or other components of the general transcriptional machinery (Smith et al. 2001). Recent work has indicated that there can be a strong link between transcription termination and reinitiation via a looping mechanism (Ansari and Hampsey 2005). Thus, the MSL complex may be involved in promoting this transient association of the $5^{\prime}$ and $3^{\prime}$ ends. Recently, the genomic distribution of histone H3.3, a histone variant associated with transcription, showed increased enrichment on X-linked genes in Drosophila SL2 cells when compared to autosomal genes (Mito et al. 2005). This enrichment favors the $5^{\prime}$ ends of transcription units and so might reflect a stimulation of transcription initiation or elongation due to MSL action.

Our results suggest that the MSL complex targets genes predominantly in the context of active transcription. This is consistent with the predominance of the MSL complex in interband regions of polytene chromosomes (Bone et al. 1994) and with experiments in which enhancer sequences responsive to the GAL4 activator protein were able to create new MSL-binding sites that required the expression of GAL4 (Sass et al. 2003). At the same time, our results are also consistent with recent cytological comparisons of the elongating form of RNA polymerase II with the MSL pattern on the polytene X chromosome, in which colocalization was observed but was clearly incomplete (Kotlikova et al. 2006). For example, many genes that we identified as differentially transcribed between SL2 cells and Clone- 8 cells were unbound in both ( $22 \%$ vs. $1.2 \%$ of commonly transcribed genes). This type of gene would show a lack of colocalization of

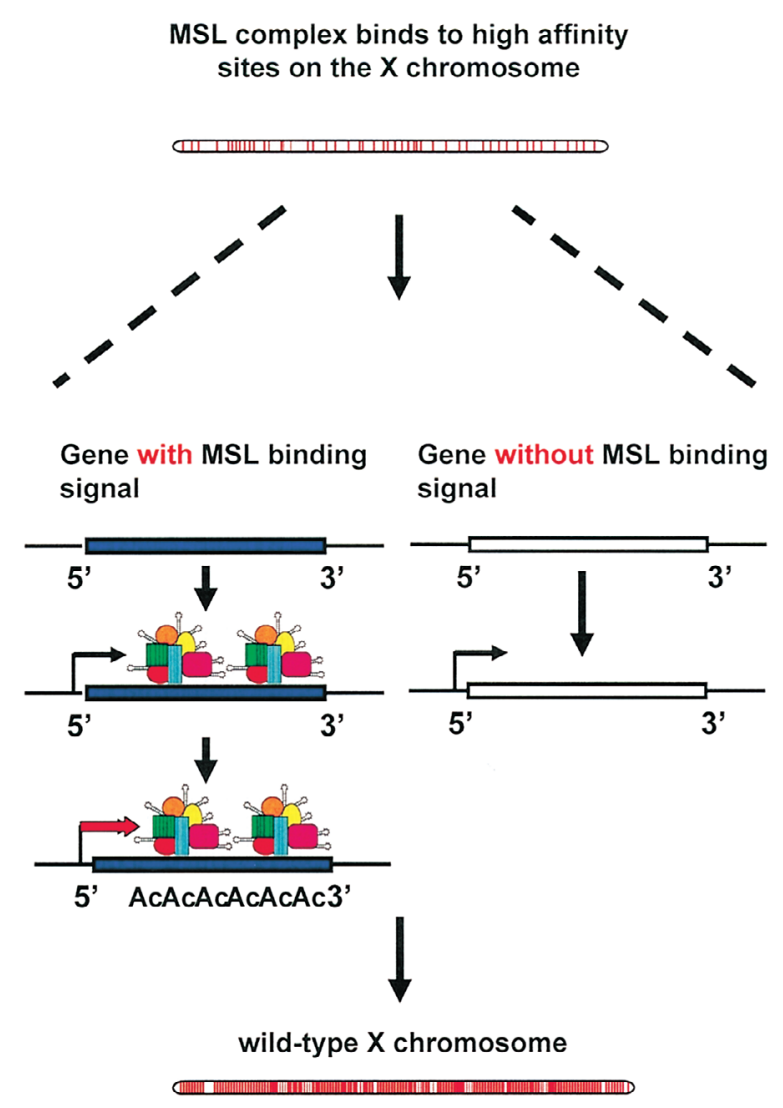

Figure 5. Model for MSL complex recruitment to expressed genes on the $\mathrm{X}$ chromosome. The MSL complex recognizes chromosomal regions distributed along the $\mathrm{X}$ chromosome based on the presence of specific sequences or noncoding RNAs. Subsequently, the MSL complex targets the 3' end of transcribed genes by interaction with histone modifications or nascent transcripts. Next, the MSL complex acetylates histone $\mathrm{H} 4$ and up-regulates active genes to equalize the dosage of transcripts of X-linked genes. Possible mechanisms for up-regulation include facilitating elongation, termination, or reinitiation of transcription.

RNA polymerase and MSL complex when transcribed. Consistent with the largely invariant pattern of MSL binding seen on polytene chromosomes by Kotlikova et al. (2006), we found that the majority of MSL targets are commonly expressed genes. Differentially regulated genes may have been less likely to evolve the ability to attract the MSL complex and perhaps may have other mechanisms to compensate for dosage differences. Our results suggest intrinsic recognition of many, but not all, $\mathrm{X}$-linked genes within the context of transcription.

Recognition of expressed genes makes excellent biological sense for the MSL complex in two ways. The most obvious is that only expressed genes need to be up-regulated. In this regard, it is notable that binding is independent of the absolute transcription level of individual genes, as dosage compensation must be able to operate on genes with a wide range of intrinsic expression levels. Another important reason to link binding to transcription may be to prevent the MSL complex from ectopically influencing genes that should not be expressed. When $r o X$ 
genes are inserted into $\mathrm{P}$ transposons and mislocalized at random positions in the genome, they attract the MSL complex, which can spread from the site of insertion into flanking chromatin (Kelley et al. 1999). In several instances, such insertions have occurred in regions where the mini-white reporter gene is silenced in females, but activated in males through action of the MSL complex (Kelley and Kuroda 2003). MSL action appeared to have the capacity to overcome Polycomb, HP1, and unidentified modes of silencing. Clearly, the MSL complex must normally be limited in its targeting to avoid potentially catastrophic male-specific activation of silent genes. Our results suggest that the MSL complex is excluded from clusters of nontranscribed genes present on the X chromosome (Fig. 2, black genes). Clustering of transcribed and nontranscribed genes in domains along the $\mathrm{X}$ chromosome is consistent with previous analysis of Drosophila chromosome 2L (Spellman and Rubin 2002).

How does the MSL complex locate its target genes? Studies of roX genes suggest that spreading in cis can occur from high local concentrations of the MSL complex. An interesting extension of this idea is that covering large segments of transcription units may occur by a very local spreading mechanism related to the much longer range spreading that can be seen from ro $X$ transgenes inserted on autosomes. Both long-range and local spreading could be the consequence of an attraction of the MSL complex to chromatin modifications that mark RNA polymerase II transcription units, such as histone H3 methylated at lysine 36 (Carrozza et al. 2005; Keogh et al. 2005; Rao et al. 2005).

In vivo and in vitro data indicate that the recruitment of the Saccharomyces cerevisiae Rpd3 small complex, $\operatorname{Rpd} 3(\mathrm{~S})$, to the $3^{\prime}$ end of transcribed genes requires histone $\mathrm{H} 3$ methylated at lysine 36 (H3K36Me) (Carrozza et al. 2005; Keogh et al. 2005; Rao et al. 2005). Rpd3(S) deacetylates histones in the wake of transcription, reseting the chromatin state and preventing abberant initiation of transcription at cryptic promoters within genes. The Eaf3 protein component of Rpd3(S) contains a chromodomain and is an MSL3 homolog. Appropriate targeting of Rpd3(S) to nucleosomes containing H3K36Me requires the Eaf3 chromodomain, suggesting that the MSL3 chromodomain may be involved in the identification of histone modifications present on transcribed genes. Distinguishing expressed genes from the bulk of the genome is likely to be an important conserved function common to many chromatin organizing and modifying activities. Future studies will examine how roX RNAs facilitate MSL targeting and the role of histone modifications and nascent mRNAs in MSL complex recruitment.

\section{ACKNOWLEDGMENTS}

We are grateful to members of the Kuroda lab for many helpful discussions. This work was supported by the National Institutes of Health (GM45744 to M.I.K. and GM67825 to P.J.P.), a grant to E.L., a Leukemia and Lymphoma Society Fellow (5198-05), and the Howard Hughes Medical Institute. M.I.K. is an HHMI Investigator.

\section{REFERENCES}

Ansari A. and Hampsey M. 2005. A role for the CPF 3'-end processing machinery in RNAP II-dependent gene looping. Genes Dev. 19: 2969.

Alekseyenko A.A., Larschan E., Lai W.R., Park P.J., and Kuroda M.I. 2006. High-resolution ChIP-chip analysis reveals that the Drosophila MSL complex selectively identifies active genes on the male X chromosome. Genes Dev. 20: 848.

Bone J.R., Lavender J., Richman R., Palmer M.J., Turner B.M., and Kuroda M.I. 1994. Acetylated histone H4 on the male X chromosome is associated with dosage compensation in Drosophila. Genes Dev. 8: 96.

Carrozza M.J., Li B., Florens L., Suganuma T., Swanson S.K., Lee K.K., Shia W.J., Anderson S., Yates J., Washburn M.P., and Workman J.L. 2005. Histone H3 methylation by Set2 directs deacetylation of coding regions by Rpd3S to suppress spurious intragenic transcription. Cell 123: 581.

Demakova O.V., Kotlikova I.V., Gordadze P.R., Alekseyenko A.A., Kuroda M.I., and Zhimulev I.F. 2003. The MSL complex levels are critical for its correct targeting to the chromosomes in Drosophila melanogaster. Chromosoma 112: 103.

Fagegaltier D. and Baker B.S. 2004. X chromosome sites autonomously recruit the dosage compensation complex in Drosophila males. PLoS Biol. 2: 1854.

Gilfillan G.D., Straub T., de Wit E., Greil F., Lamm R., van Steensel B., and Becker P.B. 2006. Chromosome-wide genespecific targeting of the Drosophila dosage compensation complex. Genes Dev. 20: 858.

Hamada F.N., Park P.J., Gordadze P.R., and Kuroda M.I. 2005. Global regulation of X chromosomal genes by the MSL complex in Drosophila melanogaster. Genes Dev. 19: 2289.

Hilfiker A., Hilfiker-Kleiner D., Pannuti A., and Lucchesi J.C. 1997. mof, a putative acetyl transferase gene related to the Tip60 and MOZ human genes and to the SAS genes of yeast, is required for dosage compensation in Drosophila. EMBO J. 16: 2054.

Kelley R.L. and Kuroda M.I. 2003. The Drosophila roXI RNA gene can overcome silent chromatin by recruiting the male-specific lethal dosage compensation complex. Genetics 164: 565.

Kelley R.L., Meller V.H., Gordadze P.R., Roman G., Davis R.L., and Kuroda M.I. 1999. Epigenetic spreading of the Drosophila dosage compensation complex from roX RNA genes into flanking chromatin. Cell 98: 513.

Keogh M.C., Kurdistani S.K., Morris S.A., Ahn S.H., Podolny V., Collins S.R., Schuldiner M., Chin K., Punna T., Thompson N.J., Boone C., Emili A., Weissman J.S., Hughes T.R., Strahl B.D., Grunstein M., Greenblatt J.F., Buratowski S., and Krogan N.J. 2005. Cotranscriptional set2 methylation of histone $\mathrm{H} 3$ lysine 36 recruits a repressive Rpd3 complex. Cell 123: 593.

Kim T.H., Barrera L.O., Zheng M., Qu C., Singer M.A., Richmond T.A., Wu Y., Green R.D., and Ren B. 2005. A high-resolution map of active promoters in the human genome. Nature 436: 876.

Kizer K.O., Phatnani H.P., Sibata Y., Hall H., Greenleaf A.L., and Strahl B.D. 2005. A novel domain in Set2 mediates RNA polymerase II interaction and couples histone $\mathrm{H} 3$ methylation with transcript elongation. Mol. Cell. Biol. 25: 3305.

Kotlikova I.V., Demakova O.V., Semeshin V.F., Shloma V.V., Boldyreva L.V., Kuroda M.I., and Zhimulev I.F. 2006. The Drosophila dosage compensation complex binds to polytene chromosomes independently of developmental changes in transcription. Genetics 172: 963.

Kuroda M.I., Kernan M.J., Kreber R., Ganetzky B., and Baker B.S. 1991. The maleless protein associates with the X chromosome to regulate dosage compensation in Drosophila. Cell. 66: 935.

Legube G., McWeeney S.K., Lercher M.J., and Akhtar A. 2006. $\mathrm{X}$-chromosome wide profiling of MSL-1 distribution and dosage compensation in Drosophila. Genes Dev. 20: 871.

Meller V.H. and Rattner B.P. 2002. The roX genes encode redundant male-specific lethal transcripts required for targeting of the MSL complex. EMBO J. 21: 1084. 
Mito Y., Henikoff J.G., and Henikoff S. 2005. Genome-scale profiling of histone H3.3 replacement patterns. Nat. Genet. 37: 1090 .

Oh H., Bone J.R., and Kuroda M.I. 2004. Multiple classes of MSL binding sites target dosage compensation to the $\mathrm{X}$ chromosome of Drosophila. Curr. Biol. 14: 481.

Oh H., Park Y., and Kuroda M.I. 2003. Local spreading of MSL complexes from roX genes on the Drosophila male $\mathrm{X}$ chromosome. Genes Dev. 17: 1334.

Park Y., Kelley R.L., Oh H., Kuroda M.I., and Meller V.H. 2002. Extent of chromatin spreading determined by roX RNA recruitment of MSL proteins. Science 298: 1620.

Rao B., Shibata Y., Strahl B.D., and Lieb J.D. 2005. Dimethylation of histone $\mathrm{H} 3$ at lysine 36 demarcates regulatory and nonregulatory chromatin genome-wide. Mol. Cell. Biol. 25: 9447 .

Ren B., Robert F., Wyrick J.J., Aparicio O., Jennings E.G., Simon I., Zeitlinger J., Schreiber J., Hannett N., Kanin E., Volkert T.L., Wilson C.J., Bell S.P., and Young R.A. 2000. Genome-wide location and function of DNA binding proteins. Science 290: 2306.

Sass G.L., Pannuti A., and Lucchesi J.C. 2003. Male-specific lethal complex of Drosophila targets activated regions of the $\mathrm{X}$ chromosome for chromatin remodeling. Proc. Natl.
Acad. Sci. 100: 8287.

Shogren-Knaak M., Ishii H., Sun J.M., Pazin M.J., Davie J.R., and Peterson C.L. 2006. Histone H4-K16 acetylation controls chromatin structure and protein interactions. Science 311: 844 .

Simic R., Lindstrom D.L., Tran H.G., Roinick K.L., Costa P.J., Johnson A.D., Hartzog G.A., and Arndt K.M. 2003. Chromatin remodeling protein Chd1 interacts with transcription elongation factors and localizes to transcribed genes. EMBO J. 22: 1846.

Smith E.R., Allis C.D., and Lucchesi J.C. 2001. Linking global histone acetylation to the transcription enhancement of Xchromosomal genes in Drosophila males. J. Biol. Chem. 276: 31483 .

Spellman P.T. and Rubin G.M. 2002. Evidence for large domains of similarly expressed genes in the Drosophila genome. J. Biol. 1: 5 .

Straub T., Gilfillan G.D., Maier V.K., and Becker P.B. 2005. The Drosophila MSL complex activates the transcription of target genes. Genes Dev. 19: 2284.

Turner B.M., Birley A.J., and Lavender J. 1992. Histone H4 isoforms acetylated at specific lysine residues define individual chromosomes and chromatin domains in Drosophila polytene nuclei. Cell 69: 375 . 


\section{$8_{\mathrm{CSH}}^{\infty}$ Cold Spring Harbor Symposia SYMPOSIA on Quantitative Biology}

\section{MSL Complex Associates with Clusters of Actively Transcribed Genes along the Drosophila Male X Chromosome}

E. LARSCHAN, A.A. ALEKSEYENKO, W.R. LAI, et al.

Cold Spring Harb Symp Quant Biol 2006 71: 385-394

Access the most recent version at doi:10.1101/sqb.2006.71.026

References This article cites 31 articles, 20 of which can be accessed free at: http://symposium.cshlp.org/content/71/385.full.html\#ref-list-1

\section{License}

Email Alerting Receive free email alerts when new articles cite this article - sign up in Service the box at the top right corner of the article or click here. 